\title{
A escrita na formação de professores de língua portuguesa
}

\author{
Fabiane Aparecida Pereira* \\ Sandro Braga**
}

\begin{abstract}
Resumo
Este artigo objetiva analisar o discurso documental presente no Projeto Pedagógico do curso de Letras/Português, da modalidade presencial, da Universidade Federal de Santa Catarina (UFSC), campus Florianópolis, no que se refere, especificamente, às práticas de escrita na formação do professor de língua portuguesa. A escrita na universidade relaciona-se ao processo de letramento acadêmico, ou seja, com os usos da escrita — e da leitura — em práticas sociais e culturais no contexto universitário, por meio dos quais ocorre a interpretação, a compreensão e a organização do conhecimento em práticas de escrita dos mais variados gêneros e temáticas. Nessa perspectiva, problematizamos, sob a ótica da Análise de Discurso, a maneira como o discurso documentalinstitucional propõe e projeta a relação do acadêmico com as práticas de escrita durante o processo de formação. Desse modo, não deixamos de considerar a memória institucional e discursiva que historiciza e permeia a constituição dos dizeres analisados. Finalmente, consideramos que a constituição das práticas de escrita acadêmica é uma necessidade fundamental no processo de formação de professores de língua portuguesa, e, nesse contexto, o discurso documental e institucional colabora para o norteamento das ações no âmbito acadêmico e para a cristalização, manutenção ou atualização de conhecimentos e práticas pedagógicas, inclusive as relacionadas à escrita.
\end{abstract}

Palavras-chave: Escrita acadêmica. Formação. Professor de Língua portuguesa.

\section{The writing in Portuguese language teachers' formation}

\section{Abstract}

This article aims to analyze the documentary discourse present in the Pedagogical Project of the course of Language Course/Portuguese, of the face-to-face modality, of the Universidade Federal de Santa Catarina (UFSC), Florianópolis campus, regarding writing practices in the formation of the Portuguese language teacher. The writing in the university is related to the process of academic literacy, that is, with the uses of writing - and reading - in social and cultural practices in the university context, through which the interpretation, understanding and organization of knowledge occurs in writing practices of the most varied genres and themes. In this perspective, we discuss, from the perspective of Discourse Analysis, the way in which the documentaryinstitutional discourse proposes and projects the relation of the academic to the writing practices during the formation process. In this way, we do not fail to consider the institutional and discursive memory that historicizes and permeates the constitution of the words analyzed. Finally, we consider that the constitution of academic writing practices is a fundamental necessity in the process of formation of Portuguese language teachers, and in this context, the documentary and institutional discourse collaborates to guide the actions in the academic scope and for the crystallization, maintenance or updating of pedagogical knowledge and practices, including those related to writing.

Keywords: Academic Writing. Formation. Portuguese language teacher.

Recebido: 18/03/2019

Aceito: $26 / 07 / 2019$

\footnotetext{
* Universidade Federal de Santa Catarina (UFSC). Doutoranda em Linguística pela Universidade Federal de Santa Catarina (UFSC). Mestra em Estudos Linguísticos pela Universidade Federal da Fronteira Sul (UFFS).

** Universidade Federal de Santa Catarina (UFSC). Mestre e doutor em Linguística. Professor Adjunto da Universidade Federal de Santa Catarina, no Departamento de Língua e Literatura Vernáculas. Professor do Programa de Pós-Graduação em Linguística no âmbito da linha de pesquisa Estudos do Campo Discursivo.
} 


\section{Introdução}

O processo formativo universitário é tido como uma prática educacional que tem como função a formação profissional, assim, é caracterizado como um bem público, pois visa "à formação de indivíduos sociais, cuja construção pessoal integral se insere no plano mais amplo da construção da sociedade [...]" (DIAS SOBRINHO, 2013, p. 110). Dessa forma, refletir sobre a formação de professores de língua portuguesa implica a ponderação a respeito de como se compõe esse importante processo de direcionamento da atuação profissional do sujeito que, também, constitui-se nesse lugar de um saber específico; um saber que o autorizará a usar a língua para dizer da própria língua.

Nessa perspectiva, uma das mais importantes premissas é a de que o discurso documentalinstitucional materializado em projetos pedagógicos, currículos, ementas, pareceres, legislações, entre outros documentos oficiais que regem a estruturação e a organização dos cursos de Letras, tem papel essencial na determinação dos saberes que circulam na esfera acadêmica e no processo formativo do professor de língua portuguesa.

O que deve ser salientado é que o discurso documental e o institucional colaboram para o norteamento das ações no âmbito acadêmico e para a cristalização, manutenção ou atualização de conhecimentos e práticas pedagógicas, uma vez que esses discursos são formados por arquivos documentais, resultantes da existência de dois tipos de arquivos. $\mathrm{O}$ arquivo é entendido como o “[...] campo de documentos pertinentes e disponíveis sobre uma questão" (PÊCHEUX, 1997, p. 57), e uns são mais acessados em sua forma de documento e produzem uma espécie de memória coletiva, enquanto outros são menos acessíveis, mas decisivos para que os documentos tenham uma interpretação que se sobreponha a qualquer outra possível. É a partir daí que entra o trabalho do simbólico, atuando no modo de produzir sentido para e por sujeitos, por isso devemos tomar o cuidado de "[...] fazer a leitura de arquivo sempre considerando a opacidade da língua e a sua historicidade, de olhar para o arquivo como discursividades" (ROMÃO; FERREIRA; DELASILVA, 2011, p. 14).

Destacamos a necessidade de que esse discurso permeado pela historicidade dos próprios saberes produzidos pelos discursos científicos, moldado por distintas condições de produção e afetado pela memória institucional e discursiva seja objeto das práticas de escrita dos componentes da formação do professor de português. Nessa perspectiva, problematizamos, sob a ótica da Análise de Discurso (AD), a maneira como o discurso documental-institucional propõe e projeta a relação do acadêmico com as práticas de escrita durante o processo de formação.

Dessa forma, optamos, neste estudo, pela análise do discurso documental presente no Projeto Pedagógico, doravante PP, do curso de Letras/Português, Licenciatura e Bacharelado, da modalidade presencial, da Universidade Federal de Santa Catarina, doravante UFSC, campus Florianópolis, no que se refere à discursividade sobre as práticas de escrita na formação do professor de língua portuguesa. Compreendemos que os preceitos basilares à formação do docente, presentes no projeto pedagógico de um curso de Letras, dizem muito sobre os modos como o sujeito acadêmico-professor em formação irá se relacionar com as práticas de escrita na universidade.

Para isso, não deixamos de considerar a memória institucional e discursiva que historiciza e permeia a constituição dos dizeres relativos à escrita presentes no PP analisado. A memória institucionalizada evidenciada no discurso documental "[...] tem relações complexas com o saber discursivo, ou seja, com o interdiscurso, que é a memória irrepresentável, que constitui ao longo de toda uma história de experiência da linguagem" (ORLANDI, 2002, p. 11). A memória discursiva deve ser entendida como uma memória "[...] não no sentido diretamente psicologista da 'memória individual', mas nos sentidos entrecruzados da memória mítica, da memória social inscrita em práticas, e da memória construída do historiador" (PÊCHEUX, 2010, p. 50). 
Sabemos que a escrita acadêmica relaciona-se ao processo de letramento acadêmico, ou seja, com os usos da escrita - e da leitura — em práticas sociais e culturais no contexto universitário, por meio dos quais ocorre a interpretação, a compreensão e a organização do conhecimento em práticas de escrita dos mais variados gêneros e temáticas. Desse modo, “[...] ao lermos e escrevermos textos-enunciados na universidade, estamos, sobretudo, nos situando em uma dada circunstância, em dado momento histórico, nas condições de dada situação social" (PEREIRA; BRAGA, 2015, p. 304-305).

Sendo assim, consideramos que o papel da escrita na formação do docente de língua portuguesa é fundamental para a constituição de um sujeito reflexivo, crítico e consciente de sua responsabilidade no ensino da escrita aos alunos. Nesse sentido, a escrita acadêmica desponta como parte integrante da atividade de linguagem e da formação do professor, pois envolve a produção de sentidos, a compreensão, a interpretação e a organização dos conhecimentos que circulam no meio acadêmico. Pela escrita na universidade emerge "[...] a possibilidade de o sujeito poder operar sobre e com a linguagem de modo singular, através da mobilização de elementos linguístico-discursivos que acabam por produzir marcas que caracterizam tentativas de produção do conhecimento" (FABIANO-CAMPOS, 2010, p. 79).

Desse modo, a reflexão sobre o foco dado à escrita, nesse processo de formação profissional de um sujeito que atuará na formação de outros sujeitos, é importante na medida em que contribui para a discussão acerca do letramento acadêmico e, mais especificamente, do propósito do ensino da escrita na universidade com vistas para a formação de professores de língua portuguesa.

\section{A escrita acadêmica}

Ao escrever, o sujeito, inserido em condições de produção específicas, vê-se diante da necessidade de fazer escolhas para que seu projeto discursivo se efetive em texto, ou seja, opta por determinadas construções em sua escrita para materializar o seu dizer e, assim, investe em certos sentidos e não em outros, em uma tentativa de constituir-se como autor. Desse modo, podemos afirmar que

[...] o que caracteriza a autoria é a produção de um gesto de interpretação, ou seja, na funçãoautor o sujeito é responsável pelo sentido do que diz, em outras palavras, ele é responsável por uma formulação que faz sentido. O modo como ele faz isso é que caracteriza sua autoria. Como, naquilo que lhe faz sentido, ele faz sentido. Como ele interpreta o que o interpreta. (ORLANDI, 1996, p. 97).

Nesse processo de constituição concomitante do sujeito como acadêmico e professor em formação, a produção de sentidos ocorre também nas práticas de escrita na universidade, como uma materialização que singulariza o sujeito, mas, ao mesmo tempo, é social e, desse modo, reverbera vozes distintas características de um interdiscurso científico que ressoa através do tempo e da historicidade, permeado pela memória institucional e discursiva.

As práticas de escrita que permeiam essa fase formativa são constitutivas tanto do lugar quanto do próprio sujeito na posição de aluno universitário, bem como fazem parte do processo para o desenvolvimento das habilidades que se espera no tocante à produção desse aluno, que é, ao mesmo tempo, estudante, professor de português em formação e, ainda, precisa ser autor de seu projeto discursivo, pois, “[...] na universidade, como na vida social em geral, ao usar a língua, nas diferentes e múltiplas situações sociais, axiologicamente, assume-se diferentes papéis" (PEREIRA; BRAGA, 2015, p. 313). Nessa ação, o sujeito adentra em um espaço de produção dos mais variados tipos de conhecimento no qual circulam problemas, respostas, paráfrases, novidades e representações do discurso do outro e de si. 
Ainda nessa ótica, sabemos que a escrita, no contexto universitário, envolve os traços de um sujeito que escreve, se inscreve e deixa suas "marcas" no texto, tendo em vista que, em toda "[...] produção escrita, deve haver uma filiação simbólica, transmissão de uma herança, de marcas, de um nome" (FABIANO-CAMPOS, 2010, p. 79). No entanto, na universidade, essas marcas acabam por fazer transparecer, também, os rastros de um sujeito dividido entre o seu próprio dizer e o dizer do outro que o autoriza a dizer na esfera acadêmica. Além disso, no caso específico do aluno-professor em formação, recai, ainda, a pressão decorrente da ilusão de um necessário saber absoluto da/sobre a língua, uma vez que este será um profissional das Letras.

Ao escrever e se inscrever em seus textos, o aluno faz tentativas de apropriação de um discurso que considera verdadeiro. No âmbito da escrita acadêmica, circulam as condições de produção e de existência da língua escrita baseadas no discurso científico, que "[...] sempre produz efeitos de verdade" (PEREIRA, 2013, p. 213). Ao posicionar-se como produtor da verdade, o acadêmico coloca-se em diferentes lugares, pois, “[...] ao escrever na universidade, estamos, dentre outras ações, instituindo relações sociais e nos posicionando em papéis específicos: aluno, acadêmico, pesquisador, profissional em formação, etc.” (PEREIRA; BRAGA, 2015, p. 313).

Esse processo é tido como fundamental, pois a constituição do sujeito-autor ocorre de modo heterogêneo, uma vez que o sujeito-acadêmico escreve e se inscreve em seus textos no afã de constituirse discursivamente como futuro profissional detentor de habilidades e competências específicas. Cabe pontuar que imergir em práticas de escrita acadêmica, assim como em toda e qualquer forma de escrita, é um ato que ressoa em diversos âmbitos das práticas sociais, tendo em vista que tais práticas são uma ferramenta fortemente alçada a um simbólico de grande prestígio social e, por isso mesmo, produzem, no imaginário, a ideia do que seja uma vida pautada pela formação, na cultura, na vida social e profissional do sujeito.

\section{0 discurso documental-institucional: memórias em jogo}

Ao mobilizarmos a $\mathrm{AD}$ para o desenvolvimento desta discussão, visamos a compreender esse discurso permeado pela historicidade de outros discursos e que se relaciona com a memória institucional, constituinte da historicidade e da identidade das instituições. A memória institucional "cristaliza" e "estabiliza" discursos dentro de universidades e na sociedade, sendo "[...] aquela que não esquece, ou seja, a que as Instituições [...] praticam, alimentam, normatizando o processo de significação, sustentando-o em uma textualidade documental, contribuindo na individualização dos sujeitos pelo Estado" (ORLANDI, 2006, p. 5).

Nesse viés, além da memória institucional, é fundamental a observação dos já-ditos, das materialidades discursivas já formuladas anteriormente, ou seja, é necessário olhar para a memória discursiva que produz regularidades em um discurso, uma vez que "[...] o discurso é construído a partir do discurso do outro, que é o ‘já dito’ sobre o qual qualquer discurso se constrói, ou seja, numa relação de alteridade" (BRAGA; ACOSTA-PEREIRA, 2016, p. 1.514). A memória discursiva seria o que, diante de um texto, “[...] surge como acontecimento a ler, vem reestabelecer os 'implícitos' (quer dizer, mais tecnicamente, os pré-construídos, elementos citados e relatados, discursos-transversos, etc.) de que sua leitura necessita: a condição do legível em relação ao próprio legível" (PÊCHEUX, 2010, p. 52).

A consideração da memória institucional e da memória discursiva na discussão sobre como o discurso documental-institucional mobiliza a questão da escrita na formação de professores de língua portuguesa é condição sine qua non para o entendimento de como os discursos instauram-se, repetemse e modificam-se ao longo da história. Nesse sentido, tomamos o Projeto Pedagógico objeto deste 
trabalho na expectativa de apontar como os diferentes discursos que permeiam a sociedade vão sendo mobilizados na construção de um documento institucional de direcionamento de uma política de formação profissional em Letras.

\subsection{0 curso de Letras e o Projeto Pedagógico: constituição do corpus}

A análise das discursividades relativas às práticas de escrita previstas no PP de um curso que norteia ações no processo de formação do sujeito-aluno para atuar como professor da disciplina de Língua portuguesa permite a reflexão sobre o papel dessas propostas na sua formação para o exercício profissional. Outro fator que merece destaque é o de que, geralmente, as experiências, os exemplos e o aprendizado teórico e prático adquiridos durante a formação refletem nas práticas e nas escolhas teóricas e metodológicas dos professores em sua atuação nas escolas.

“[...] Onde e como é que se formam esses professores que dão aula no primário e no secundário [...]? [...] o aluno da universidade está sendo capacitado para sua prática?" (ORLANDI, 2008, p. 31). São questionamentos como esses que suscitam a necessidade de investigação das práticas que perpassam os cursos de licenciatura. Compreender a constituição dos cursos de Letras é essencial para que haja o entendimento acerca do processo de escrita pelo sujeito-acadêmico-professor em formação, pois o modo como o discurso documental-institucional de um curso de Letras contempla as práticas de escrita na universidade reflete na formação dos professores de língua portuguesa.

Dessa forma, problematizamos a construção de sentidos do/no discurso documental-institucional do curso de Letras da UFSC, que forma sujeitos com vistas à atuação, principalmente, na Educação Básica, na mediação entre o aluno e a sua própria língua, tomada nesse espaço como objeto de conhecimento. Iniciamos nosso trabalho de análise pela metodologia adotada em análise do discurso, ou seja, "pela configuração do corpus, delineando-se seus limites, fazendo recortes, na medida mesma em que se vai incidindo um primeiro trabalho de análise, retomando-se conceitos e noções". (ORLANDI, 2009, p. 67). Em análise do discurso, metodologicamente, temos a mobilização de um dispositivo teórico ao mesmo tempo em que se dá a construção de um dispositivo analítico a partir das escolhas que são tomadas como exemplares do corpus e que servem de sequências em que se pode observar o funcionamento da discursividade. Optamos, para o desenvolvimento desta pesquisa, pela seleção e análise de recortes de excertos do discurso documental referente à escrita presente no PP do curso de Letras/Português, da modalidade presencial, da UFSC, campus Florianópolis, no que se refere às práticas de escrita na formação do professor de língua portuguesa.

Os licenciados em Letras/Português dessa Instituição atuarão, provavelmente, como docentes de língua portuguesa em escolas públicas e privadas da região, em todo o estado de Santa Catarina ou outras regiões do Brasil. Diante disso, busca-se compreender e refletir sobre as práticas de escrita que estão previstas no PP do curso, tendo em vista que a escrita acadêmica constitui-se como uma das atividades que entendemos ser de relevância singular no percurso de formação de professores de língua portuguesa, haja vista que toma a língua como objeto de ensino e aprendizagem da própria língua numa relação de via dupla, primeiramente, com o próprio discente e, a posteriori, quando este se torna docente.

O PP do curso foi concebido coletivamente, por meio do trabalho de comissões do Departamento de Língua e Literatura Vernáculas (DLLV), que atuaram desde 2003 na Instituição, visando à elaboração e organização das propostas e do currículo do curso. O curso de Letras/Português da UFSC contempla três grandes áreas de ensino: Língua Portuguesa/Linguística, Literatura e Latim.

Cabe ressaltar que há um núcleo comum à Licenciatura e ao Bacharelado, isto é, a organização curricular é a mesma para ambas as formações profissionais até a quarta fase (diurno) e até a quinta 
fase (noturno). Após esse período, são diferentes as disciplinas obrigatórias, bem como as disciplinas optativas, as práticas e as atividades acadêmico-científico-culturais. Nesse sentido, novamente, o envolvimento em/com diferentes práticas de escrita parece ser singular para o sujeito-aluno em formação, principalmente, dada a possibilidade de percursos distintos em um processo formativo que teve um início comum.

\section{A escrita na formação de professores de língua portuguesa}

A formação de professores de língua portuguesa é um processo no qual o sujeito-acadêmico — que, nesse período, também está na posição de sujeito-professor em formação — vivencia experiências tanto educacionais, como sociais e de contato com variados saberes sobre a língua, inclusive os referentes à escrita. Nesse contexto, os documentos institucionais orientadores do curso de Letras devem ser atentamente produzidos, considerando a necessidade de observação das transformações sociais e culturais, a integração entre a teoria e a prática e a orientação profissional.

Consoante o Parecer CNE/CES, nº 492/2001, o objetivo do curso de Letras é formar profissionais "[...] interculturalmente competentes, capazes de lidar, de forma crítica, com as linguagens, especialmente a verbal, nos contextos oral e escrito, e conscientes de sua inserção na sociedade e das relações com o outro" (CONSELHO NACIONAL DE EDUCAÇÃO, 2001, p. 30, grifo nosso). O objetivo do documento evidencia a orientação legislativa de que o foco da formação deve ser o desenvolvimento de competências linguísticas para uso em variados contextos comunicativos e de uso da linguagem, bem como para a constituição da criticidade, da reflexividade e da ação no meio sociocultural. Nota-se que a escrita ganha espaço na formulação e constituição do objetivo geral, portanto, sua relevância parece ser reconhecida.

O PP do curso de Letras/Português, Licenciatura e Bacharelado, da modalidade presencial, da UFSC, campus Florianópolis, aborda a questão do preparo do profissional de Letras para a atuação comprometida com a ética, com a responsabilidade social e educacional. Nesse âmbito, ressalta a importância da formação continuada, da consciência dos efeitos de sua atuação como mediador do processo de ensino-aprendizagem e do aprimoramento profissional. Em um primeiro recorte do PP, tem-se como objetivo do curso:

[...] formar profissionais (professores e bacharéis) competentes, em termos de (in)formação e autonomia, capazes de lidar de forma sistemática, reflexiva e crítica com temas e questões relativos a conhecimentos linguísticos e literários, em diferentes contextos de oralidade e escrita. (UNIVERSIDADE FEDERAL DE SANTA CATARINA, 2006, p. 8, grifo nosso).

A consideração da escrita no objetivo geral do PP do curso explicita a relevância que a prática possui na formação do acadêmico. Nota-se que a discursividade dos diferentes documentos - o Parecer CNE/CES no 492/2001 e o PP/LETRAS/UFSC — dialoga no sentido de que a escrita, juntamente com aspectos relacionados à oralidade e a conhecimentos linguísticos e literários, é constitutiva do desenvolvimento da criatividade, da reflexividade, da criticidade e proatividade do sujeito. Nessa direção, percebemos como novas discursividades em torno do imaginário do que seja um professor de português vão adentrando e constituindo o discurso documental desse PP. Pode-se dizer que há algum tempo havia um outro imaginário - o de que o professor de Língua portuguesa era aquele sujeito detentor de um conhecimento total da língua pátria, enquanto os demais sujeitos seriam meros falantes de uma língua menor, não reconhecida. Nesse cenário, cabia ao professor de português dizer o que era certo e o que era errado. Não é à toa que resquícios desse discurso ainda circulam socialmente, e não tem sido trabalho fácil para a sociolinguística desfazer esses equívocos.

Nota-se como o discurso documental sempre teve grande impacto nos direcionamentos, nas ações 
pedagógicas e nas escolhas didáticas relacionadas à escrita na universidade e ao percurso de formação de professores de língua portuguesa. A partir da década de 1980, por exemplo, uma renovação da visão sobre o curso de Letras propiciou mudanças na organização curricular e na estruturação do curso em diversas universidades, pois houve

[...] um contexto propício para uma reforma geral no jardim das Letras. Uma reforma que substitua a pauta tradicional de tais discussões - cartorial e corporativista — por uma pauta estrutural e conjuntural, que dê conta da radical alteração do objeto em nome do qual os cursos de Letras se criaram e se mantêm até hoje. A questão não é curricular. É estrutural. Nasce e desemboca na forma de inserção do curso de Letras na sociedade brasileira contemporânea. (LAJOLO, 2009, p. 10).

Nessa perspectiva, são revistas as práticas consideradas como relevantes para a constituição do curso de Letras, que passa a valorizar ações universitárias e escolhas curriculares que estejam em consonância com a sociedade que rodeia a instituição. É o espaço para a constituição de novos discursos num movimento entre o parafrástico e o polissêmico, entre o velho e o novo, a partir do que já foi dito sobre a língua e a escola e o que passa a ser possível ser dito nessas esferas. Desse modo, o documento produzido dentro das condições de produção da universidade passa a fazer um sentido que reflete e refrata uma política de formação historicamente marcada, e é essa historicização que dará o tom para o documento atualizar-se como monumento, ou melhor, como um discurso documental.

O PP/LETRAS/UFSC sinaliza que o documento foi elaborado absorvendo as necessidades provenientes da evolução e mudanças ocorridas na sociedade e na formação de professores e profissionais da linguagem. Além disso, num segundo recorte, frisa que, independentemente da habilitação escolhida, Licenciatura ou Bacharelado, o profissional de Letras deve ser capaz de:

a) compreender e usar adequadamente a língua portuguesa no que se refere a sua estrutura, funcionamento e manifestações culturais;

b) ter consciência das variedades linguísticas e culturais historicamente constituídas, e da significação social das mesmas;

c) ler e produzir textos adequados a diferentes situações discursivas;

d) transitar por diferentes perspectivas teóricas nas investigações linguísticas e literárias, abordando-as criticamente;

e) analisar e refletir criticamente acerca de conteúdos referentes a estudos linguísticos e literários e à formação profissional;

f) estabelecer um diálogo entre a sua área e as demais áreas do conhecimento;

g) compreender a formação profissional como processo contínuo, autônomo e permanente, à luz da dinâmica do mercado de trabalho. (UNIVERSIDADE FEDERAL DE SANTA CATARINA, 2006, p. 9, grifos nossos).

O rol de capacidades consideradas como essenciais ao profissional de Letras certamente esboça pontos relevantes a serem contemplados no processo de formação, dentre eles, a prática da escrita. Complementando as expectativas expostas no PP do curso de Letras da UFSC, temos, nas Diretrizes Curriculares Nacionais dos cursos de Letras, aprovadas em 3 de abril de 2001, pelo Parecer CNE/CES $n^{\circ} 492 / 2001$, a perspectiva de que os cursos deverão apresentar estruturas organizacionais flexíveis que:

- facultem ao profissional a ser formado opções de conhecimento e de atuação no mercado de trabalho; 
- criem oportunidade para o desenvolvimento de habilidades necessárias para se atingir a competência desejada no desempenho profissional;

- deem prioridade à abordagem pedagógica centrada no desenvolvimento da autonomia do aluno;

- promovam articulação constante entre ensino, pesquisa e extensão, além de articulação direta com a pós-graduação;

- propiciem o exercício da autonomia universitária, ficando a cargo da Instituição de Ensino Superior definições como perfil profissional, carga horária, atividades curriculares básicas, complementares e de estágio. (CONSELHO NACIONAL DE EDUCAÇÃO, 2001, p. 29).

É visível que as proposições documentais-institucionais apresentadas convergem para um discurso calcado na ilusão de possibilidade da existência de um sujeito completo e absoluto na perspectiva de uma formação de sujeitos autônomos e preparados para a atuação profissional. Dito de outro modo, formar sujeitos (professores) para o trabalho de formar sujeitos (alunos) para o trabalho nas mais diversas áreas.

Destacamos um terceiro recorte do PP/LETRAS/UFSC, no qual temos que o graduado em Letras — pesquisador ou professor — deverá ser identificado por competências e habilidades adquiridas no decorrer do curso, como:

- Domínio da língua portuguesa em sua norma culta e em suas manifestações oral e escrita.

- Uso adequado da língua em diferentes situações de comunicação.

- Reflexão analítica e crítica sobre a linguagem como fenômeno social, psicológico, educacional, histórico, cultural, político e ideológico.

- Visão crítica das perspectivas teóricas adotadas nas investigações linguísticas e literárias, que fundamentam a formação do profissional das Letras.

- Percepção de diferentes contextos interculturais.

- Formação profissional atualizada, de acordo com a dinâmica do mercado de trabalho.

- Utilização de recursos de novas tecnologias.

- Aptidão para atuar, interdisciplinarmente, em áreas afins. (UNIVERSIDADE FEDERAL DE SANTA CATARINA, 2006, p. 9-10).

Ao contemplar a "escrita" entre os objetivos do curso, nota-se uma preocupação com a constituição do professor, que, por sua vez, no exercício da profissão, deve ser comprometido em propor práticas de escrita ao aluno. O desafio é pensarmos na escrita acadêmica como parte de processos distintos, mas que se relacionam. Nesse viés, temos, de um lado, a forma e a função da escrita na formação universitária e, de outro, a forma e a função da escrita na atuação profissional como professor, na ação de ensinar e inserir o aluno em práticas de escrita.

Em um quarto recorte, expomos a organização curricular do curso de Letras, no que tange à referência direta à escrita materializada pela produção e/ou redação. Conforme já mencionamos, há um núcleo comum tanto para o bacharelado quanto para a licenciatura, até a quarta fase, para o diurno, e até a quinta fase, para o noturno. É fato que as práticas de escrita são contempladas em todas as disciplinas do curso, por meio da produção de textos acadêmicos como artigos, resenhas, resumos, relatórios, entre outros, porém nosso foco, neste estudo, são as discursividades que guiam 
a oferta de disciplinas no PP/LETRAS/UFSC (representante também da organização curricular) que mencionam, de modo mais direto, a escrita como objeto de ensino e aprendizagem. Assim, temos os seguintes recortes organizados nas Tabelas 1 e 2 :

Tabela 1 - A escrita no currículo como Disciplina Obrigatória

\begin{tabular}{|c|l|l|l|}
\hline $\begin{array}{c}\text { DISCIPLINA } \\
\text { OBRIGATÓRIA }\end{array}$ & FASE & $\begin{array}{c}\text { CARGA } \\
\text { HORÁRIA }\end{array}$ & \multicolumn{1}{c|}{ EMENTA } \\
\hline $\begin{array}{l}\text { Produção Textual } \\
\text { Acadêmica I }\end{array}$ & $1^{\text {a }}$ & $\begin{array}{l}\text { 60h/aula }(52 \mathrm{~h} \\
\text { t e o r i a } / 8 \mathrm{~h} \\
\text { PCC) }\end{array}$ & $\begin{array}{l}\text { Estudo e produção de textos técnico-científicos relevantes para } \\
\text { o desempenho das atividades acadêmicas, tais como: resumo, } \\
\text { resenha, artigo e seminário. Reflexões sobre a prática pedagógica } \\
\text { no ensino fundamental e médio. }\end{array}$ \\
\hline
\end{tabular}

Fonte: Os autores. (Adaptado do PP, 2006).

Tabela 2 - A escrita no currículo como Disciplina Optativa

\begin{tabular}{|l|l|l|}
\hline \multicolumn{1}{|c|}{ DISCIPLINA OPTATIVA } & CARGA HORÁRIA & \multicolumn{1}{c|}{ EMENTA } \\
\hline $\begin{array}{l}\text { NORMA PADRÃO } \\
\text { ESCRITA I }\end{array}$ & $60 \mathrm{~h} / \mathrm{a}(30 \mathrm{PCC})$ & Aspectos do uso da língua padrão escrita - estrutura frasal. \\
\hline $\begin{array}{l}\text { NORMA PADRÃO } \\
\text { ESCRITA II TEXTUAL }\end{array}$ & $60 \mathrm{~h} / \mathrm{a}(30 \mathrm{PCC})$ & Aspectos do sistema ortográfico. Emprego de palavras. \\
\hline $\begin{array}{l}\text { PRODUÇÃO } \\
\text { ACADEMICA II }\end{array}$ & $\begin{array}{l}\text { Estudo e produção de textos técnico-científicos relevantes } \\
\text { para o desempenho das atividades acadêmicas, tais como: } \\
\text { projeto de pesquisa e monografia. }\end{array}$ \\
\hline $\begin{array}{l}\text { REDAÇÃO OFICIAL E } \\
\text { EMPRESARIAL }\end{array}$ & $\begin{array}{l}\text { Estudo e produção de documentos e correspondências } \\
\text { oficiais e empresariais. }\end{array}$ \\
\hline
\end{tabular}

Fonte: Os autores. (Adaptado do PP, 2006).

As escolhas curriculares são permeadas por uma memória institucional que, por sua vez, é constituída historicamente por relações de poder e ideologias que produzem os efeitos de sentido dos dizeres e dos silenciamentos decorrentes das relações de força das políticas institucionais, que podem ser observadas pelo modo como ocorre a estruturação e a organização regimental de cada universidade. $\mathrm{O}$ currículo mostra “[...] a concretização da própria escola e a forma particular de enfocá-la num momento histórico e social determinado, para um nível ou modalidade de educação, numa trama institucional" (SACRISTÁN, 2000, p. 15). Assim, é nesse importante elemento da documentação institucional que se mostram as escolhas determinantes dos modos como a forma-sujeito aluno será moldada e, por consequência, como os sujeitos constituir-se-ão nesses lugares ao ascenderem a essa posição de estudantes universitários em formação docente, por exemplo, baseados por políticas educacionais e correntes de ensino salientes à(s) época(s) e em determinadas condições de produção.

Cabe-nos salientar que o currículo faz parte da gama dos discursos documentais que se repetem e se atualizam pelo interdiscurso e referem-se a uma memória institucional e discursiva que perpassa as instituições e os discursos nela produzidos no interior de uma historicidade que se encontra em constante (re)formulação. Ao analisarmos discursivamente as nomeações das disciplinas que se relacionam diretamente à escrita, sabemos que o "processo de nomeação de uma disciplina é de fundamental importância, pois entendemos ser este um ato político no interior da instituição" (MARTINS, 2012, p. 24). 
Ao pensarmos na nomeação Produção Textual Acadêmica I, podemos nos reportar aos recortes do próprio PP que contemplam a indicação da prática de escrita como um dos objetivos do curso e como habilidade a ser desenvolvida pelos acadêmicos. Todavia, é necessário conhecermos e pensarmos sobre que discurso está em jogo nos documentos institucionais dos cursos de Letras, inclusive nos currículos. Neles, destaca-se a carga de relevância atribuída às práticas de escrita no decorrer do processo formativo do professor de língua portuguesa. Mas os questionamentos que surgem a partir dessa atribuição também são merecedores de reflexão, pois é necessário pensarmos com que propósito se escreve na universidade e como isso contribui para a formação do professor, como a escrita acadêmica reverbera na atuação do profissional nas escolas, na condução dos alunos no processo de escrita. Um ponto que deve ser ressaltado é o de que, no contexto acadêmico, o professor em formação é, antes, um sujeito-aluno, que tem expectativas, depara-se com dificuldades e desafios e almeja estar preparado para produzir satisfatoriamente os textos acadêmicos propostos nas disciplinas de seu curso.

Ao lançarmos um olhar sobre o percurso histórico do ensino da língua portuguesa no Brasil, vislumbramos que a escrita - e a leitura - são práticas que ganham maior destaque em sala de aula a partir da década de 1990 (SOARES, 2004). Nota-se, a partir dessa época, que "os processos de leitura e escrita passam, portanto, a ser resultantes da interação autor-texto-leitor" (CLARE, 2003, p. 23). A disciplina de Produção Textual Acadêmica I focaliza práticas de escrita, embora somente para as específicas do âmbito acadêmico e, além disso, propõe a reflexão sobre a prática pedagógica no Ensino Fundamental e Médio, o que demonstra uma perspectiva de interligação entre os saberes adquiridos na universidade e a atuação no meio profissional com os alunos.

Entretanto, é necessário pensar que há uma ruptura entre a escrita do professor em formação na universidade e a escrita na qual ele deve se pautar ao dar aulas de língua portuguesa aos alunos nas escolas. Trata-se de uma considerável mudança de perspectiva, tendo em vista que a escrita acadêmica é ensinada com o intuito de possibilitar ao aluno conhecer as técnicas de escrita de gêneros textuais que geralmente circulam na universidade, como resenhas, resumos, artigos, trabalhos de conclusão, entre outros. Esses gêneros, geralmente, não são contemplados nas propostas de produção de texto nas escolas. ${ }^{1}$

Temos, ainda, no rol das Disciplinas Optativas: Norma Padrão Escrita I, Norma Padrão Escrita II, Produção Textual Acadêmica II e Redação Oficial e Empresarial. Ao analisarmos a nomeação Norma Padrão Escrita, temos a referência ao seguimento do caráter normativo e estrutural nas práticas de escrita, que se liga a discursos bastante arraigados nos estudos do estruturalismo, gramática e ortografia. No Brasil, o estudo da estrutura dos textos e palavras foi contemplado desde o surgimento dos cursos de Letras - e nas escolas _- passando por avanços entre a década de 1950 e 1960, quando a gramática e o texto passam a ser estudados de modo articulado. Ainda hoje, o estudo de estruturas linguísticas do idioma é foco dos processos de ensino-aprendizagem da escrita em muitas universidades que formam professores de língua portuguesa.

No que tange à Redação Oficial e Empresarial, pensamos que essa nomeação e essa ementa constituem-se de uma memória discursiva que se relaciona com o ensino tecnicista-instrumental que remete aos primeiros cursos superiores no Brasil, a partir de 1825, que visavam à formação para a atuação profissional técnica. O foco, nesse caso, recai sobre um ensino direcionado para o aprendizado de estruturas e técnicas para a produção da redação oficial, que engloba documentações e textos que circulam em esferas oficiais. Isso aponta para uma certa contradição em relação à proposta do PP,

1 Cabe notar que os gêneros resumo e resenha até podem ser ensinados e praticados no Ensino Médio, no entanto, com finalidades distintas das da Graduação. Na universidade, o resumo, por exemplo, costuma ser trabalhado em sua relação de independência com o texto-fonte (resumo informativo) e de dependência (resumo indicativo); já a resenha geralmente é pensada em sua especificidade de possibilidade de posicionamento crítico frente ao próprio campo do conhecimento científico. 
uma vez que pensar por um lado a "produção textual” com vistas à promoção do sujeito e sua acessão à autoria vai na contramão de uma "redação oficial" que expurga o sujeito do seu lugar de dizer para subjugá-lo a modelos de escrita de documentos ditos oficiais.

Com essa breve análise das nomeações dos componentes curriculares, vemos que, muitas vezes, há lacunas no que se refere aos aspectos contemplados nas ementas das disciplinas, privilegiando-se apenas alguns pontos dentro das inúmeras possibilidades de estudo. Um dos fatores que deve sempre ter atenção especial na elaboração dos currículos é o de que a formação do professor de língua portuguesa precisa contemplar o estudo da linguagem em suas múltiplas facetas, por meio de práticas de leitura e escrita que tenham relação com as práticas sociais, o que refletirá também em sua prática como docente.

Dando continuação à análise dos recortes do PP, o quinto excerto apresenta o que o PP expõe em relação aos procedimentos metodológicos e às formas de avaliação. Tem-se, então, que:

Dada a especificidade do Curso de Letras, a avaliação deve ser centrada nas práticas de leitura/escritura, na capacidade de posicionamento crítico face às diferentes teorias linguísticas e literárias, bem como de ensino da disciplina de Língua Portuguesa na educação básica, na formulação de novos conceitos diante do canônico, do instituído e do consagrado, especialmente em função do papel político e sociocultural inerente à formação do profissional em Letras. Nesse sentido, deve-se considerar também a inserção dos alunos na prática de iniciação científica e na elaboração e execução de práticas pedagógicas. (UNIVERSIDADE FEDERAL DE SANTA CATARINA, 2006, p. 100, grifo nosso).

Sendo assim, o PP/LETRAS/UFSC prevê, no processo avaliativo, a consideração das práticas de escrita do aluno, além dos demais aspectos como o desenvolvimento da consciência crítica e reflexiva perante os conhecimentos adquiridos. Em um sexto recorte do PP/LETRAS/UFSC, temos que, no decorrer do processo formativo:

Devem ser considerados, entre outros, os seguintes aspectos: adoção de instrumentos diversificados de avaliação (trabalhos escritos individuais e em grupo, com e sem consulta, produzidos em sala e fora dela; seminários; relatórios; resenhas; autoavaliação; etc.); validação das atividades acadêmicas por instâncias competentes; orientação acadêmica individualizada (prevista no plano de ensino como 'horário de atendimento'). Particularmente, espera-se que seja trabalhada, em cada disciplina, a prática de produção/ revisão de textos acadêmicos sobre os objetos específicos de cada campo de estudos. (UNIVERSIDADE FEDERAL DE SANTA CATARINA, 2006, p. 101, grifos nossos).

O processo avaliativo prevê, nesse viés, o alcance do objetivo proposto no $\mathrm{PP}$, que visa à formação do pesquisador/professor autônomo e qualificado para atuar profissionalmente de maneira ampla e eficaz. A avaliação, nesse sentido, não deve ser tida como instrumento de classificação ou poder, mas como um meio de verificação da aprendizagem, auxiliando no direcionamento das práticas pedagógicas do curso.

Outra discussão que entra em destaque ao tratarmos sobre a escrita acadêmica é a respeito das dificuldades do aluno perante as práticas de escrita propostas na universidade, seja em cursos presenciais ou a distância. O que se evidencia é o fato de que "essa escrita exige que os alunos tenham habilidades de construir um texto, trabalhando, de forma coerente, as múltiplas vozes dos autores referenciados e a sua própria voz. Essa habilidade precisa ser ensinada para que o aluno desenvolva um letramento acadêmico sólido" (KERSH; SANTOS, 2017, p. 90).

Outro ponto que provoca debates é a anunciada decepção dos professores universitários com a qualidade dos textos produzidos pelos acadêmicos, principalmente no início do curso, fato que, muitas vezes, remete à qualidade do ensino recebido na Educação Básica. O que ocorre, também, é a criação de uma expectativa por parte desses mesmos docentes de que o acadêmico pode/deve escrever bons textos, independentemente do gênero, assim que isso lhe for solicitado. Todavia: 
As práticas de letramento próprias do meio acadêmico são muito distintas daquelas a que o aluno estava acostumado no ensino médio. Isso, provavelmente, distancia a escrita dos acadêmicos das propostas dos professores, uma vez que a maioria deles não tem o domínio da linguagem acadêmica, que precisa ser aprendida (e ensinada). O professor do ensino superior, por sua vez, parece assumir que ensinar a escrever gêneros que circulam na esfera acadêmica não é tarefa sua e que o aluno deveria vir com essas competências e habilidades desenvolvidas. (KERSH; SANTOS, 2017, p. 92).

Sob essa ótica, os estudos dos letramentos acadêmicos apontam para a necessidade de que a universidade dê atenção a esse processo, reveja as práticas de leitura e escrita que permeiam as ações didáticas e pedagógicas do curso e preocupe-se em preparar o acadêmico e dar o devido suporte para que este se sinta capaz e motivado a escrever e constituir-se como autor, protagonista de sua escrita, recebendo todas as orientações necessárias para o desenvolvimento de habilidades e competências nas práticas de escrita. E, sob a perspectiva da análise do discurso, tem-se a linguagem como não transparente e o sentido como efeito do discurso. Dito de outro modo, aquilo que o sujeito diz, sob a ilusão de ser a origem desse dizer, é de certo modo determinado pelas condições de produção do sentido e do próprio sujeito que se põe a dizer, assim, cabe pontuar, então, que a universidade é peçachave na constituição dessas condições.

Sabemos que, ao final do curso, o acadêmico poderá não ser considerado um especialista em práticas de escrita, mas tem-se uma perspectiva, de acordo com os excertos emergidos do PP/ LETRAS/UFSC, de que o aluno, agora professor, tenha a habilidade de reconhecer a relevância do ensino da escrita aos futuros alunos e de conhecer os principais meios de transpor os conhecimentos adquiridos na universidade para a sala de aula. Nesse sentido, o questionamento acerca dos documentos institucionais faz-se necessário, pois pode haver uma certa contradição entre o que é exposto nesses discursos e o que efetivamente ocorre na universidade.

\section{Considerações finais}

Ao optarmos pela análise de um discurso documental-institucional, devemos considerar que trabalhamos com um objeto histórico-discursivo, sujeito “[...] a um real sócio-histórico que demanda sentidos. Os acontecimentos produzem efeitos sobre a documentação, fazendo irromper novas práticas ou interromper aquelas em andamento" (NUNES, 2008, p. 96). Nesse viés, somos confrontados com a necessidade de produzir gestos de interpretação perante uma memória institucionalizada, que, mesmo aparentemente cristalizada, sempre evidencia (novos) efeitos de sentido. Desse modo, ao analisarmos um documento institucional, precisamos considerar que o político está sempre presente atravessando a formulação, a constituição e a circulação dessa modalidade discursiva, já que é atravessado por relações de poder, ideologias presentes nas condições de produção inerentes a cada época.

Percebe-se, no PP/LETRAS/UFSC, a presença de discussões que remetem à atuação futura do então acadêmico na sociedade, com foco em sua ação profissional como mediador do processo de ensinoaprendizagem da língua portuguesa. Nossa análise sobre como as práticas de escrita contempladas na formação do acadêmico que exercerá seu papel de sujeito-docente objetivou a reflexão em relação a como isso refletirá nas práticas pedagógicas direcionadas ao sujeito-aluno. De certo modo, apesar de algumas contradições, o discurso documental-institucional do projeto pedagógico analisado aponta para uma tentativa de materializar nesse documento o que a sociedade vem discursivizando historicamente acerca do tratamento da língua como ferramenta de possibilidade de mudança social por aqueles que dominam certos gêneros discursivos valorados socialmente.

Ao debater sobre a temática da formação de professores, problematizamos sobre as dificuldades que emergem com o ingresso no contexto universitário, como dúvidas, problemas e desafios inerentes 
ao processo de descoberta e inserção em um novo contexto de ensino-aprendizagem. Esses percalços ganham destaque no que se refere à escrita na universidade, envolvendo diversos aspectos que incidem no direcionamento dessas práticas e no modo como são desenvolvidas. Está em jogo o trabalho dos professores universitários, as ementas das disciplinas, o desempenho do aluno, a prática, o conhecimento dos mecanismos e gêneros, os meios didáticos, enfim, tudo o que cerca esse período de formação profissional.

São as condições de produção em contexto amplo - o modo como a universidade está constituída sócio-historicamente - e o contexto imediato - a forma possível de o sujeito-aluno em formação atualizar seu discurso - que possibilitam a formação de um profissional de Letras. Desse modo, observar como a universidade prospecta em seu projeto pedagógico o processo de ensino e aprendizagem de práticas de escrita torna possível, também, uma projeção de como o acadêmico de Letras poderá constituir sua relação com a escrita de modo a percebê-la como uma ferramenta de apropriação de conhecimentos, bem como reconheça a função da escrita em sua formação na esfera acadêmica e em sua atuação no mundo profissional.

Especificamente a respeito da escrita acadêmica proposta na universidade, podemos compreendêla como um gesto de fazer com que o acadêmico perceba ainda mais a necessidade de que temos de apropriarmo-nos de gêneros textuais mais complexos em certas esferas de comunicação humana, pois é dessa forma que a comunicação se dá em esferas sociais mais especializadas. Desse modo, o dizer produzido na universidade poderá ressoar também no exercício da profissão e no cotidiano dos alunos, pois a escrita acadêmica "[...] não significa escrever para a universidade, mas para a vida" (KERSH; SANTOS, 2017, p. 93).

\section{Referências}

BRAGA, S.; ACOSTA-PEREIRA, R. A inscrição do sujeito na escrita acadêmica numa perspectiva dialógica. Fórum Linguístico, Florianópolis, v. 13, n. 3, p. 1.506-1.524, jul./set. 2016. Disponível em: <https://periodicos.ufsc.br/index.php/forum/article/view/1984-8412.2016v13n3p1506>. Acesso em: 15 fev. 2019.

CONSELHO NACIONAL DE EDUCAÇÃO. Câmara de Educação Superior (CNE/CES). Parecer CNE/CES no 492/2001, aprovado em 3 de abril de 2001. Aprova as Diretrizes Curriculares Nacionais dos cursos de Arquivologia, Biblioteconomia, Ciências Sociais - Antropologia, Ciência Política e Sociologia, Comunicação Social, Filosofia, Geografia, História, Letras, Museologia e Serviço Social. Diário Oficial da União, Brasília, DF, Seção 1e, p. 50, 9 jul. 2001. Disponível em: $<$ http://portal.mec.gov.br/conselho-nacional-de-educacao/atos-normativos--sumulas-pareceres-eresolucoes?id=12991>. Acesso em: 10 fev. 2019.

CLARE, Nícia de Andrade Verdini. Ensino de língua portuguesa: uma visão histórica. Revista Idioma, Rio de Janeiro, n. 23, p. 7-24, 2003. Disponível em: <http://www.institutodeletras.uerj.br/ idioma/numeros/23/idioma23a01.pdf>. Acesso em: $1^{\circ}$ fev. 2019.

DIAS SOBRINHO, José. Educação superior: bem público, equidade e democratização. Avaliação, Campinas, Sorocaba, SP, v. 18, n. 1, p. 107-126, mar. 2013.

FABIANO-CAMPOS, Sulemi. O uso de conectores como um recurso do "recorta e cola" em escrita acadêmica. Revista do GELNE, Piaú, v. 12, n. 2, p. 75-80, 2010.

KERSH, Dorotea Frank; SANTOS, Fernando César dos. Escrita acadêmica e desenvolvimento de autoria na formação de professores via Ead: as universidades estão preparadas? Raído, Dourados, MS, v. 11, n. 25, p. 89-108, jan./jun. 2017.

LAJOLO, Marisa. No jardim das letras, o pomo da discórdia. Unicamp, 2009. Disponível em: 
$<$ http://www.unicamp.br/iel/memoria/projetos/ensaios/ensaio36.html>. Acesso em: 10 fev. 2019.

MARTINS, Taís da Silva. Efeitos de sentido na disciplinarização de uma teoria. 2012. Tese (Doutorado em Letras) - Centro de Artes e Letras, Universidade Federal de Santa Maria, Santa Maria, RS, Brasil, 2012.

NUNES, José Horta. O discurso documental na história das ideias linguísticas e o caso dos dicionários. Alfa, São Paulo, v. 52, n. 1, p. 81-100, 2008.

ORLANDI, Eni Puccinelli. Interpretação: autoria, leitura e efeitos do trabalho simbólico. Petrópolis, RJ: Vozes, 1996.

ORLANDI, Eni Puccinelli. Língua e conhecimento linguístico: para uma história das ideias no Brasil. São Paulo: Cortez, 2002.

ORLANDI, Eni Puccinelli. Análise de discurso. In: ORLANDI, Eni P.; RODRIGUES, Suzy Maria Lagazzi (Orgs.). Introdução às ciências das linguagens: discurso e textualidade. Campinas-SP: Pontes Editores, 2006. p. 11-31.

ORLANDI, Eni Puccinelli. Discurso e leitura. 8. ed. São Paulo: Cortez, 2008.

ORLANDI, Eni Puccinelli. Análise de discurso: princípios e procedimentos. 8. ed. Campinas: Pontes, 2009.

PÊCHEUX, Michel. Ler o arquivo hoje. In: ORLANDI, E. P. (org.). Gestos de leitura: da história no discurso. Tradução de Maria das Graças Lopes Morin do Amaral. Campinas, SP: UNICAMP, 1997. p. 55-66.

PÊCHEUX, Michel. Papel da memória. In: ACHARD, Pierre et al. Papel da memória. 3. ed. Campinas, SP: Pontes Editores, 2010. p. 39-57.

PEREIRA, M. V. A escrita acadêmica do excessivo ao razoável. Revista Brasileira de Educação, v. 18, n. 52, p. 213-144, jan./mar. 2013.

PEREIRA, Rodrigo Acosta; BRAGA, Sandro. Ler e escrever na universidade: um fazer sóciohistórico-cultural. Linguagem em (Dis)curso - LemD, Tubarão, SC, v. 15, n. 2, p. 303-320, maio/ ago. 2015 .

ROMÃO, Lucília Maria Sousa; FERREIRA, Maria Cristina Leandro; DELA-SILVA, Silmara. Arquivo. In: MARIANI, Bethania; MEDEIROS, Vanise; DELA-SILVA, Silmara (Orgs.). Discurso, arquivo e... . Rio de Janeiro: 7Letras, 2011. p. 11-21.

RUSSEL, David. Letramento acadêmico: leitura e escrita na universidade: entrevista com David Russell. Entrevista concedida a Flávia Brocchetto Ramos e Vânia Marta Espeiorin. Conjectura, v. 14, n. 2, p. 241-247, maio/ago. 2009.

SACRISTÁN, José Gimeno. O currículo: uma reflexão sobre a prática. Tradução de Ernani F. da Rosa. Porto Alegre: ArtMed, 2000.

SOARES, Magda. Português na escola: história de uma disciplina curricular. In: BAGNO, Marcos. Linguística da norma. São Paulo: Edições Loyola, 2004. p. 155-177.

UNIVERSIDADE FEDERAL DE SANTA CATARINA (UFSC). Projeto pedagógico do Curso de Graduação em Letras Língua Portuguesa e Literaturas de Língua Portuguesa Licenciatura e BachareladoE Florianópolis: Centro de Comunicação e Expressão, Departamento de Língua e Literatura Vernáculas, 2006. 